\title{
Conditioning of Tobacco and Tobacco Products: The Effect of Forced Air Flow *
}

by

\author{
Zhihao Chen ${ }^{1}$, Qian Miao ${ }^{1}$, Jijun Zhao ${ }^{1}$, Li Ding ${ }^{1}$, Yan Xiao ${ }^{2}$, Huiping Wang ${ }^{2}$, Yunhua Qin ${ }^{3}$, Wen Xiong ${ }^{3}, H_{o n g}$ Tao ${ }^{4}$, \\ Yu Wang ${ }^{4}$, Xiaodong $\mathrm{Lv}^{5}$, and Qian Feng ${ }^{\mathrm{I}}$
}

${ }^{1}$ Zhengzhou Tobacco Research Institute of CNTC, Zhengzhou 450001, Henan, China

${ }^{2}$ Yunnan Tobacco Quality Supervision \& Test Station, Kunming 650106, Yunnan, China

${ }^{3}$ China Tobacco Yunnan Industrial Co. Ltd., Kunming 650024, Yunnan, China

${ }^{4}$ China Tobacco Guangdong Industrial Co. Ltd., Guangzhou 510610, Guangdong, China

5 Shanghai Tobacco Group Co., Ltd., Shanghai 200082, Shanghai, China

\section{SUMMARY}

Conditioning is a very important procedure for tobacco and tobacco products before their corresponding chemical and physical analysis. For cigarettes, forced air flow is generally required during the conditioning procedure. A special wind tunnel was designed to investigate how the forced air flow affects the conditioning of cigarettes in a constant climate laboratory. Two types of cigarettes with blended (including flue-cured and burley tobacco strands) and pure flue-cured tobacco strands were selected as test samples. It was found that the conditioning time to achieve the equilibrium could be shortened from $23 \mathrm{~h}$ without forced air flow to $7 \mathrm{~h}$ with a forced air flow rate of $2 \mathrm{~m} / \mathrm{s}$. This is mainly due to the exchange of water molecules between cigarette samples and atmosphere being accelerated by applying the forced air flow. It was concluded that a $48 \mathrm{~h}$ conditioning period using the described forced air flow rate setup was unnecessary to attain the equilibrium for cigarettes. [Beitr. Tabakforsch. Int. 28 (2019) 224-229]

\section{KEY WORDS}

Conditioning; cigarettes; forced air flow; wind tunnel; equilibrium

\section{ZUSAMMENFASSUNG}

Die Konditionierung stellt ein sehr wichtiges Verfahren vor der chemischen und physikalischen Analyse von Tabak und Tabakprodukten dar. Bei Zigaretten ist während des Konditionierungsverfahrens die Anwendung eines forcierten Luftstroms (forced air flow) erforderlich. Es soll untersucht werden, wie der forcierte Luftstrom die Konditionierung von Zigaretten in einem Labor mit konstantem Raumklima beeinflusst. Hierfür wurde ein spezieller Windkanal entwickelt. Als Testproben wurden zwei Typen von Zigaretten entweder mit Tabakmischungen (mit Fasern von heißluftgetrocknetem Tabak und Burley-Tabak) oder mit reinen heißluftgetrockneten Tabakfasern ausgewählt. Es wird festgestellt, dass der forcierte Luftstrom die Konditionierungszeit bis zum Gleichgewicht von 23 Stunden ohne forcierten Luftstrom auf sieben Stunden mit einem forcierten Luftstrom von $2 \mathrm{~m} / \mathrm{s}$ verkürzt. Dies liegt hauptsächlich am schnelleren Austausch von Wassermolekülen zwischen den Zigarettenproben und der Atmosphäre aufgrund der Anwendung des forcierten Luftstroms. Für den Konditionierungszeitraum von 48 Stunden wird die Methode des forcierten Luftstroms jedoch für unnötig zur Erreichung des Gleichgewichts in Zigaretten gehalten. [Beitr. Tabakforsch. Int. 28 (2019) 224-229] 


\section{RESUME}

Le conditionnement constitue une étape essentielle dans la préparation du tabac et des produits de tabac avant leur analyse physique et chimique. Et dans le cas des cigarettes, la procédure de conditionnement requiert souvent l'utilisation d'un flux d'air pulsé. Nous avons conçu une soufflerie spéciale destinée à explorer comment le flux d'air pulsé affecte le conditionnement des cigarettes dans un laboratoire à climat constant. Deux types de cigarettes contenant tantôt des mélanges de tabac (avec des brins de tabac Burley et de tabac blond) tantôt des brins de tabac blond pur furent retenus en guise d'échantillons pour essai. Il fut observé que le flux d'air pulsé pouvait raccourcir le temps de conditionnement nécessaire pour atteindre un équilibre, le ramenant de 23 heures, sans flux d'air pulsé à 7 heures avec un flux d'air pulsé de $2 \mathrm{~m} / \mathrm{s}$. Ce phénomène est principalement lié à l'accélération des échanges de molécules d'eau entre les cigarettes et l'atmosphère lors de l'utilisation d'air pulsé. Cependant, dans le cas d'un temps de conditionnement de 48 heures, le flux d'air pulsé est jugé inutile pour atteindre l'équilibre pour les cigarettes. [Beitr. Tabakforsch. Int. 28 (2019) 224-229]

\section{INTRODUCTION}

It is well established that conditioning is of great importance for tobacco and tobacco products before chemical and physical analysis. For instance, the moisture content of tobacco strands plays a significant role during the burning (1) which could be significantly affected by the conditioning. It could then interfere with the determination of the components in the mainstream cigarette smoke, which is tightly related to the burning process (2-4). Therefore, in order to achieve uniform properties of the tested cigarette samples, cigarettes were generally conditioned at $22{ }^{\circ} \mathrm{C} \pm 1{ }^{\circ} \mathrm{C}$ and relative humidity of $60 \% \pm 3 \%$ for $48 \mathrm{~h}$, either in a constant climate chamber or in a constant climate laboratory, before their utilization for further analysis.

The aforementioned conditioning procedure for cigarettes is originally derived from ISO 3402:1999 (5). However, in this standard, cigarette conditioning is requested to be performed with "sufficient forced air flow". This could be difficult to implement, either in the constant climate chamber or laboratory, because the air flow in the constant climate chamber or laboratory cannot be precisely controlled. In addition, surprisingly, very few relevant investigations can be found about how the forced air flow rates affect cigarette conditioning.

Therefore, in this work, conditioning was investigated on cigarette samples with three different water content levels (low moisture: $\sim 3 \%$ to $5 \%$, routine: $\sim 8 \%$ to $10 \%$ and high moisture: $\sim 16 \%$ to $18 \%$ ) by applying forced air flow of different velocities in a specifically designed wind tunnel. Flue-cured cigarettes and blended cigarette were utilized to conduct the experiments. To evaluate how the forced air flow affects the cigarette conditioning, the tested sample weight was recorded every hour. The effect of conditioning was evaluated by using the equilibrium criterion provided in ISO 3402:1999.

\section{MATERIALS AND METHODS}

\subsection{Materials}

Two types of commercially available Chinese cigarettes were used in this study. The detailed information is given in Table 1.

Table 1. General information on the test samples.

\begin{tabular}{l|c|c|c}
\hline Type & Size & $\begin{array}{c}\text { Weight } \\
(\mathrm{g})\end{array}$ & $\begin{array}{c}\text { Water content } \\
(\%)\end{array}$ \\
\hline Flue-cured & King Size & 0.897 & 10.1 \\
Blended & King Size & 0.896 & 8.4 \\
\hline
\end{tabular}

To investigate how the forced air flow affects the cigarette conditioning, a wind tunnel was designed and manufactured in order to maintain the forced air flow rate stable and in a controllable range. A schematic representation of the wind tunnel setup is illustrated in Figure 1. The whole setup was placed in a constant climate laboratory $\left(22{ }^{\circ} \mathrm{C} \pm 1{ }^{\circ} \mathrm{C}\right.$ and relative humidity of $60 \% \pm 3 \%$ ). The forced air flow was generated by an air fan (YY9225H24S) delivered by SNOWFAN Company (Shenzhen, China), and was adjusted by changing the electric current. The velocity of the forced air flow was tested with an anemograph (testo 405i) placed on the top of the cigarette samples, which was obtained from TESTO Company (Lenzkirch, Germany). The temperature and the relative humidity were regularly monitored by a hygrothermograph (Wireless Probe Unit) purchased from ZOGLAB Company (Hangzhou, China). The sample weight was recorded by an analytical balance (CP224S from SARTORIUS Company, Shanghai, China) equipped with a computer.

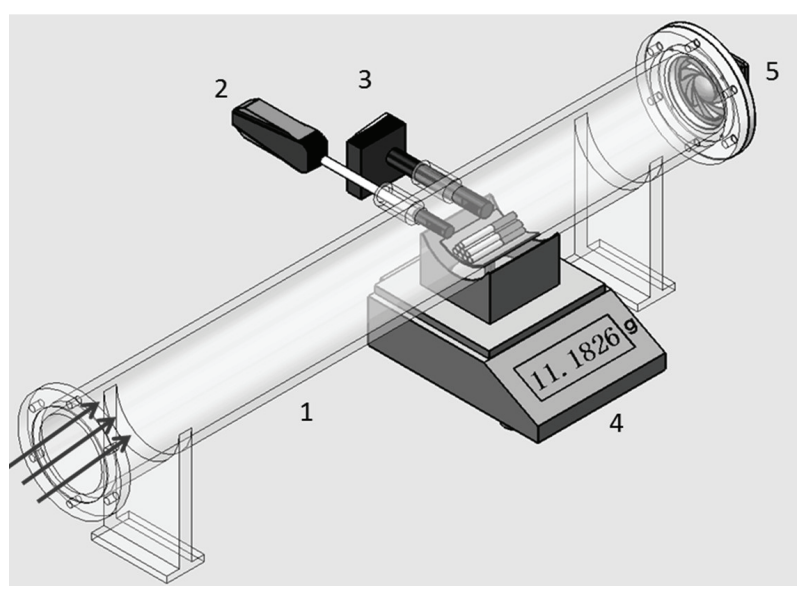

Figure 1. Schematic representation of the wind tunnel setup. 1. Length $150 \mathrm{~cm}$, inner diameter $15 \mathrm{~cm}, 2$. anemograph, 3. hygrothermograph, 4. balance, 5. air fan, arrow: direction of forced air flow

\subsection{Pretreatment of the cigarette}

All samples were selected based on that the weight difference of every cigarette is less than $\pm 0.03 \mathrm{~g}$ in comparison 
Table 2. Water content for both flue-cured and blended cigarette samples before and after pretreatment.

\begin{tabular}{l|c|c|c|c|c}
\hline \multirow{2}{*}{ Type } & \multirow{2}{*}{ Size } & \multirow{2}{*}{ Weight $(\mathrm{g})$} & \multicolumn{3}{|c}{ Water content (\%) } \\
\cline { 5 - 6 } & & & High moisture & Routine & Low moisture \\
\hline Flue-cured & King Size & \multirow{2}{*}{$0.89 \pm 0.06$} & 17.5 & 10.1 & 5.2 \\
Blended & King Size & $0.89 \pm 0.06$ & 16.9 & 8.4 & 2.7 \\
\hline
\end{tabular}

to the average. Then both flue-cured and blended cigarette samples were pretreated at $22{ }^{\circ} \mathrm{C}$ and a relative humidity of $80 \%$ to obtain the high moisture samples. For the low moisture samples, the flue-cured and blended cigarettes were dried in the oven at $70{ }^{\circ} \mathrm{C}$ for $15 \mathrm{~min}$. Routinely cigarette samples were directly used after unpacking. Water content of both flue-cured and blended samples was determined via the Karl Fischer method (6).

\subsection{Conditioning of the cigarettes in the wind tunnel}

The conditioning procedure was conducted using the wind tunnel described in Figure 1. First, 20 pieces of pretreated cigarette samples were placed in the wind tunnel, on the top of the balance. The weight was recorded as $m_{0}$. Then the air fan was turned on to establish a forced air flow with a constant velocity $(\sim 1 \mathrm{~m} / \mathrm{s}, \sim 2 \mathrm{~m} / \mathrm{s})$. Since the air came from a constant climate $\left(22^{\circ} \mathrm{C} \pm 1{ }^{\circ} \mathrm{C}\right.$ and relative humidity of $60 \% \pm 3 \%$ ), the temperature and relative humidity around the samples did not change. The cigarette samples were conditioned for $48 \mathrm{~h}$ with either no forced air flow or constant forced air flow, and the sample weight was automatically recorded every hour. The forced air flow, if used, was stopped while recording the sample mass. After $48 \mathrm{~h}$, the forced air flow, if used, was stopped and the sample mass was continuously recorded for the next $3 \mathrm{~h}$. The conditioning effect was evaluated using the following equation:

$$
\omega=\left[\frac{m_{t+3}-m_{t}}{m_{t}}\right] \times 100 \%
$$

where $\omega$ refers to the variation of the mass of samples, $m_{t}$ refers to the sample mass after $t$ hours, $m_{t+3}$ refers to the sample mass after $t+3 \mathrm{~h}$. If $\omega$ is no higher than $0.2 \%$, the equilibrium is considered to be attained. Otherwise, the cigarettes are deemed to be insufficiently conditioned (5).

\section{RESULTS AND DISCUSSION}

\subsection{Water content}

In order to get to a deeper understanding about how the forced air flow influenced the conditioning on different kinds of cigarettes, both flue-cured and blended cigarettes were pretreated to obtain samples with different water content. Their water content before and after pretreatment is given in Table 2. It could be observed that, after the pretreatment, there was a significant difference in water content.
For flue-cured cigarettes, the water content was determined to be $17.5 \%, 10.1 \%$ and $5.2 \%$ for high moisture, routine and low moisture samples, respectively. For the blended cigarettes, the water content was $16.8 \%, 8.4 \%$ and $2.7 \%$ for high moisture, routine and low moisture samples, respectively. Notably, after the sample pretreatment, the water content for blended cigarette samples was lower than that observed for flue-cured cigarettes, indicating a lower ability of blended cigarette samples for water adsorption. This might be attributed to their different composition.

\subsection{Conditioning of flue-cured cigarettes in the wind tunnel}

Flue-cured cigarette samples with three levels of water content were conditioned in the wind tunnel for $48 \mathrm{~h}$ by applying the different forced air flow rates, i.e., $0 \mathrm{~m} / \mathrm{s}$, $1 \mathrm{~m} / \mathrm{s}$ and $2 \mathrm{~m} / \mathrm{s}$. Figure 2 shows the change of mass of the high moisture samples over time with different velocities of forced air flow. It can be observed that, with applying an extra forced air flow of $2 \mathrm{~m} / \mathrm{s}$, the sample mass decreased rapidly within $10 \mathrm{~h}$ and then remained stable. In contrast, without any forced air flow, the sample weight dropped continuously during the whole conditioning process and the speed of mass decrease slowed down during the conditioning process. This can be attributed to the fact that the water content of the high moisture samples is relatively high, and the water molecules could be transferred from the tobacco strands to the atmosphere. In addition, by comparing the rate of mass decrease using forced air flow with different speeds, it is deemed that desorption of water from the cigarettes could be accelerated by utilizing the forced air flow. It was found that the conditioning for all samples met the equilibrium criterion. In detail, it took $23 \mathrm{~h}, 10 \mathrm{~h}$ and $7 \mathrm{~h}$ for the high moisture samples to meet the equilibrium by using $0 \mathrm{~m} / \mathrm{s}(\omega=0.20 \%), 1 \mathrm{~m} / \mathrm{s}(\omega=0.17 \%)$ and $2 \mathrm{~m} / \mathrm{s}$ $(\omega=0.19 \%)$ of forced air flow, respectively. This implies that the forced air flow is dispensable for conditioning cigarettes with relatively high water content.

The changing mass of low moisture samples with different forced air flow rates is shown in Figure 3. As can be seen, by utilizing $1 \mathrm{~m} / \mathrm{s}$ and $2 \mathrm{~m} / \mathrm{s}$ forced air flow, the mass of 20 cigarettes increased from $16.7 \mathrm{~g}$ to $17.7 \mathrm{~g}$ within $15 \mathrm{~h}$ and then remained unchanged until the end of the experiment. On the other hand, without forced air flow, the sample mass kept increasing during the entire procedure. And the rate of mass increase dropped during the conditioning process. It seems that as the water content of the dried samples is relatively low, water molecules are transferred from the atmosphere to the tobacco strands. In addition, similar to the desorption of water from the high moisture cigarettes, adsorption of water could be accelerated by applying a forced air flow as well. 


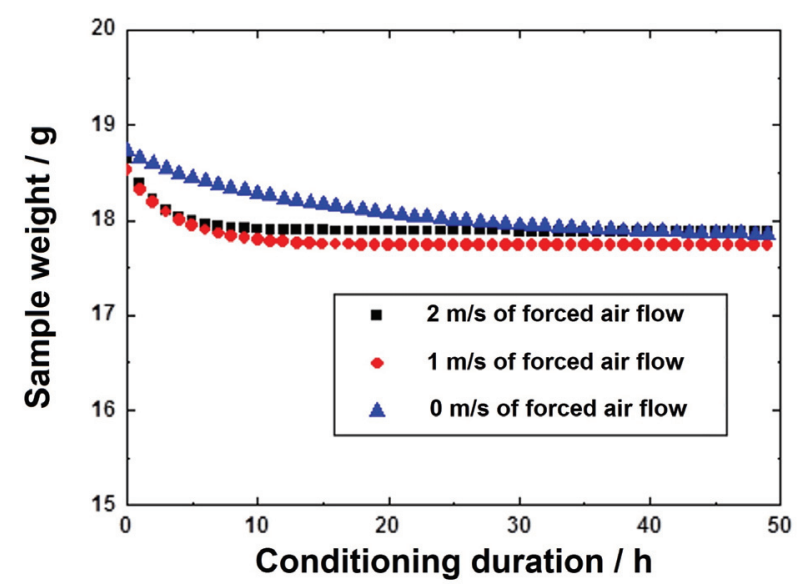

Figure 2. Mass of high-moisture cigarette samples with fluecured tobacco strands as function of conditioning duration with $0 \mathrm{~m} / \mathrm{s}, 1 \mathrm{~m} / \mathrm{s}$ and $2 \mathrm{~m} / \mathrm{s}$ of forced air flow.

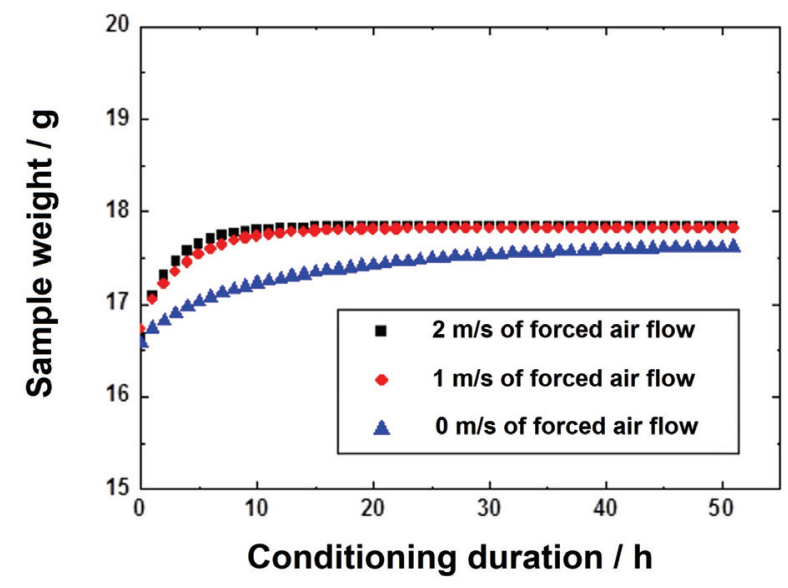

Figure 3. Mass of low-moisture cigarette samples with fluecured tobacco strands as function of conditioning duration with $0 \mathrm{~m} / \mathrm{s}, 1 \mathrm{~m} / \mathrm{s}$ and $2 \mathrm{~m} / \mathrm{s}$ of forced air flow.

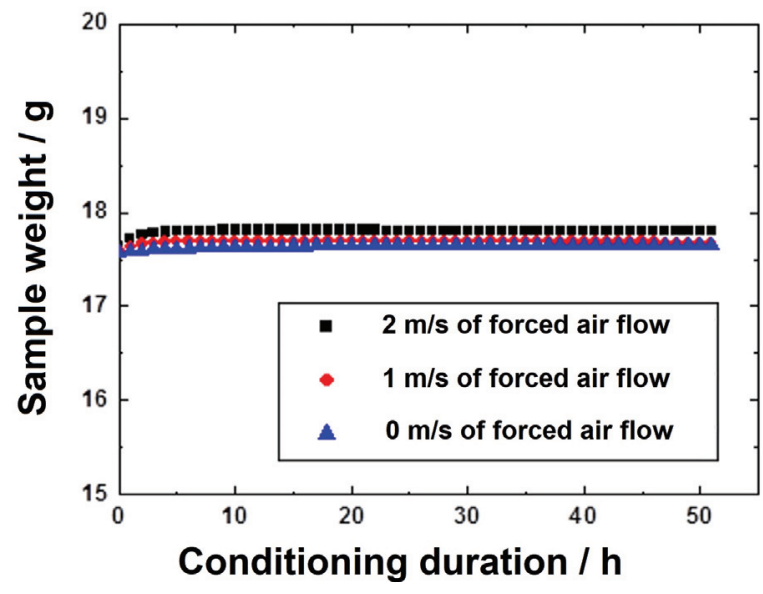

Figure 4. Mass of routine cigarette samples with flue-cured tobacco strands as function of conditioning duration with $0 \mathrm{~m} / \mathrm{s}, 1 \mathrm{~m} / \mathrm{s}$ and $2 \mathrm{~m} / \mathrm{s}$ of forced air flow.
However, by checking the mass variation, it was found that the conditioning for all samples met the equilibrium criterion within $48 \mathrm{~h}$. Particularly, it took $23 \mathrm{~h}, 11 \mathrm{~h}$ and $9 \mathrm{~h}$ for the low moisture samples to meet the equilibrium criterion by using $0 \mathrm{~m} / \mathrm{s}(\omega=0.20 \%), 1 \mathrm{~m} / \mathrm{s}(\omega=0.19 \%)$ and $2 \mathrm{~m} / \mathrm{s}(\omega=0.17 \%)$ of forced air flow, respectively. Again, this suggests that the forced air flow is not necessary for conditioning the low moisture cigarette just to achieve equilibrium.

Further, routine flue-cured samples, used directly after unpacking, were conditioned in the wind tunnel for $48 \mathrm{~h}$ with forced air flow of different speeds. The mass of the routine samples over time with different speeds of forced air flow is given in Figure 4. Unlike the high-moisture or low-moisture samples and no matter how fast the flow speed was, the sample mass remained at the same level ( $\sim 17.9 \mathrm{~g}$ for 20 cigarette samples) from the beginning until the end of the conditioning procedure, demonstrating that the equilibrium was already achieved. This is mainly due to the fact that the manufacturing of cigarettes takes place under conditions which are close to the conditioning atmosphere $\left(22{ }^{\circ} \mathrm{C}\right.$ and a relative humidity of $\left.60 \%\right)$. Anyway, the results of routine samples further prove that the forced air flow has no influence on cigarettes attaining the equilibrium for the conditioning period of $48 \mathrm{~h}$.

\subsection{Conditioning of blended cigarettes in the wind tunnel}

To further investigate the effect of forced air flow on cigarette conditioning, blended cigarettes with different water content were conditioned under forced air flow of $0 \mathrm{~m} / \mathrm{s}, 1 \mathrm{~m} / \mathrm{s}$ and $2 \mathrm{~m} / \mathrm{s}$, respectively. The mass variation of high and low moisture samples and of the routine blended samples with the application of a forced air flow of different velocities was shown in Figures 5, 6 and 7, respectively. As can be seen from Figure 5, same as for flue-cured samples, the sample mass decreased rapidly within $10 \mathrm{~h}$ and then remained steady. On the other hand, without any forced air flow, the sample weight dropped continuously during the whole conditioning process, which is also consistent with the results obtained using flue-cured cigarette samples, see Figure 2. And the speed of mass increase was much lower in comparison to that achieved with forced air flow. Furthermore, Figure 6 shows that the mass of the low moisture blended samples increased very fast under forced air flow (from $16.9 \mathrm{~g}$ to $17.7 \mathrm{~g}$ within $10 \mathrm{~h}$ ), while it kept increasing during the whole conditioning period when no the forced air flow was applied.

This agrees with the results for the flue-cured cigarette samples, see Figure 3. Again, these results suggest that the adsorption of water for the cigarette samples can be accelerated by utilizing forced air flow. Regarding the mass change of routine blended cigarettes with different forced air flow rates, practically identical results were obtained in comparison to the flue-cured samples, i.e., no obvious change of sample mass occured from the beginning until the end of the conditioning procedure.

In addition, the effect of conditioning was evaluated by checking the equilibrium of each group of blended samples. For high-moisture samples, it took $19 \mathrm{~h}, 10 \mathrm{~h}$ and $8 \mathrm{~h}$ to meet the equilibrium criterion by using $0 \mathrm{~m} / \mathrm{s}(\omega=0.20 \%)$, $1 \mathrm{~m} / \mathrm{s}(\omega=0.15 \%)$ and $2 \mathrm{~m} / \mathrm{s}(\omega=0.16 \%)$ of forced air 


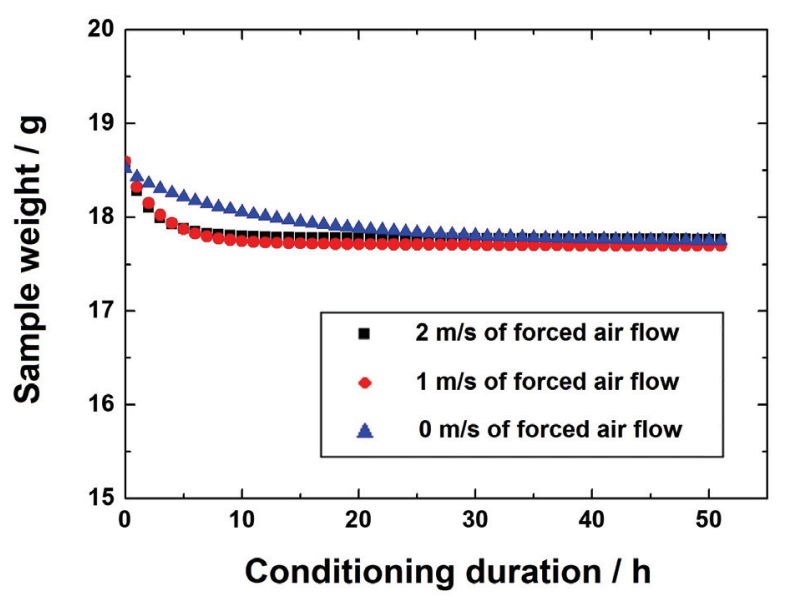

Figure 5. Mass of high-moisture cigarette samples with blended tobacco strands as function of conditioning duration with $0 \mathrm{~m} / \mathrm{s}, 1 \mathrm{~m} / \mathrm{s}$ and $2 \mathrm{~m} / \mathrm{s}$ of forced air flow.

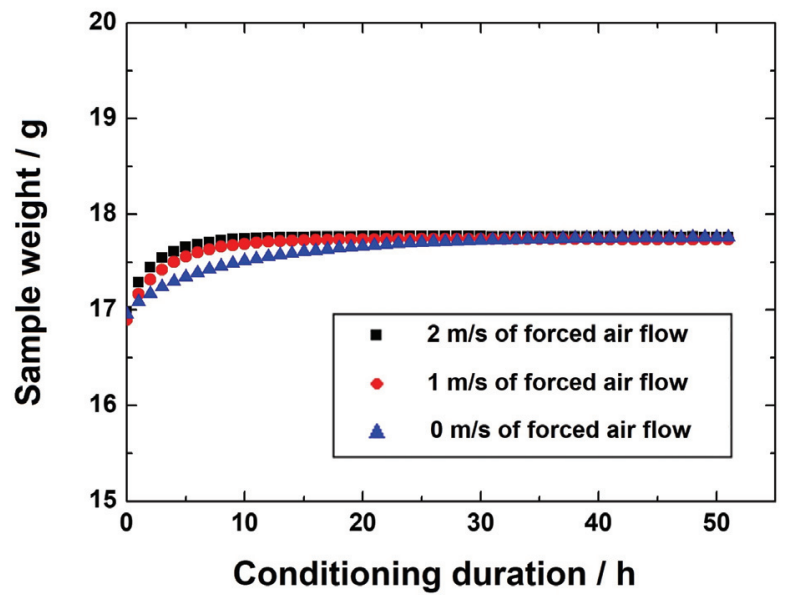

Figure 6. Mass of low-moisture cigarette samples with blended tobacco strands as function of conditioning duration with $0 \mathrm{~m} / \mathrm{s}, 1 \mathrm{~m} / \mathrm{s}$ and $2 \mathrm{~m} / \mathrm{s}$ of forced air flow.

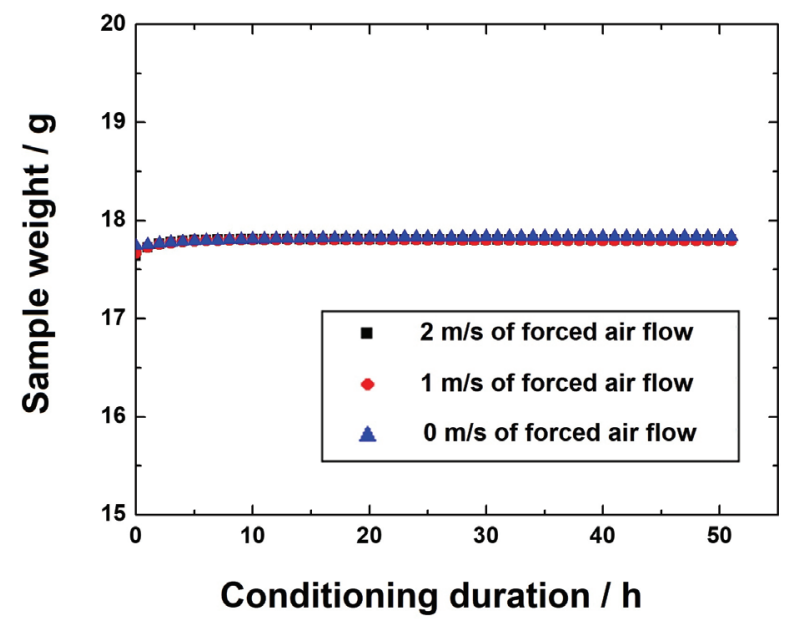

Figure 7. Mass of routine cigarette samples with blended tobacco strands as function of conditioning duration with $0 \mathrm{~m} / \mathrm{s}, 1 \mathrm{~m} / \mathrm{s}$ and $2 \mathrm{~m} / \mathrm{s}$ of forced air flow. flow, respectively. For the low-moisture samples, it took $18 \mathrm{~h}, 10 \mathrm{~h}$ and $8 \mathrm{~h}$ to meet the equilibrium criterion by using $0 \mathrm{~m} / \mathrm{s}(\omega=0.19 \%), 1 \mathrm{~m} / \mathrm{s}(\omega=0.16 \%)$ and $2 \mathrm{~m} / \mathrm{s}$ $(\omega=0.20 \%)$ of forced air flow, respectively. For the routine samples, equilibrium was obtained within $3 \mathrm{~h}$ no matter what kind of forced air flow was applied. These results further confirm that forced air flow can shorten the conditioning time to achieve the equilibrium water content for loose cigarettes. However, if a conditioning period of $48 \mathrm{~h}$ is applied, forced air flow plays no obvious role for attaining the equilibrium.

\section{CONCLUSIONS}

Conditioning of cigarette samples was investigated with three different levels of water content (low moisture: 3\% to $5 \%$, routine: $\sim 8 \%$ to $10 \%$ and high moisture: $\sim 16 \%$ to $18 \%$ ) by introducing different forced air flow rates in the wind tunnel. Flue-cured and blended cigarettes were used for the experiments. It took $23 \mathrm{~h}, 10 \mathrm{~h}$ and $7 \mathrm{~h}$ for the highmoisture flue-cured samples to reach equilibrium by using $0 \mathrm{~m} / \mathrm{s}(\omega=0.20 \%), 1 \mathrm{~m} / \mathrm{s}(\omega=0.17 \%)$ and $2 \mathrm{~m} / \mathrm{s}$ $(\omega=0.19 \%)$ of forced air flow, respectively. Furthermore, it required $23 \mathrm{~h}, 11 \mathrm{~h}$ and $9 \mathrm{~h}$ for the low-moisture fluecured samples to achieve the equilibrium by using $0 \mathrm{~m} / \mathrm{s}$ $(\omega=0.20 \%), 1 \mathrm{~m} / \mathrm{s}(\omega=0.19 \%)$ and $2 \mathrm{~m} / \mathrm{s}(\omega=0.17 \%)$ of forced air flow, respectively. In addition, the equilibrium for routine flue-cured cigarette samples was almost attained from the beginning of the conditioning procedure, indicating that the forced air flow plays no significant role during the conditioning. For the blended cigarette samples, similar results were observed. Therefore, it is concluded that forced air flow can shorten the conditioning duration to reach the equilibrium for cigarettes, but if $48 \mathrm{~h}$ of conditioning are carried out, as required in ISO 3402:1999, forced air flow is deemed to be unnecessary to attain the equilibrium for cigarettes.

\section{REFFERENCES}

1. Chen, P.S.: Chemistry of Cigarette Burning Processes; Beitr. Tabakforsch. Int. 21 (2004) 105-110. DOI: $10.2478 /$ cttr-2013-0772

2. Lewis, C.I.: The Effect of Cigarette Construction Parameters on Smoke Generation and Yield; Rec. Adv. Tob. Sci. 16 (1990) 73-101.

3. De Bardeleben, M.Z., W.E. Claflin, and W.F. Gannon: Role of Cigarette Physical Charactaristics on Smoke Composition; Rec. Adv. Tob. Sci. 4 (1978) 85-111.

4. Baker, R.R.: Product Formation Mechanisms Inside a Burning Cigarette; Prog. Energy Combust. Sci. 7 (1981) 135-153. DOI: 10.1016/0360-1285(81)90008-3

5. International Organisation for Standardization (ISO): ISO 3402:1999 — Tobacco and Tobacco Products Atmosphere for Conditioning and Testing; ISO, Geneva, Switzerland, 1999.

6. International Organisation for Standardization (ISO): ISO 6488:2004 — Tobacco and Tobacco Products Determination of Water Content - Karl Fischer Method; ISO, Geneva, Switzerland, 2004. 
Corresponding author:

Prof. Qian Feng

Zhengzhou Tobacco Research Institute of CNTC

Zhengzhou, Henan, China

E-mail:feng@ztri.com.cn 